\title{
Comparison of UVC/S2O8 2- with UVC/H2O2 in terms of efficiency and cost for the removal of micropollutants from groundwater
}

\section{Antoniou, Maria; Andersen, Henrik Rasmus}

Published in:

Chemosphere

Link to article, DOI:

10.1016/j.chemosphere.2014.03.029

Publication date:

2015

Document Version

Peer reviewed version

Link back to DTU Orbit

Citation (APA):
Antoniou, M., \& Andersen, H. R. (2015). Comparison of UVC/S $\mathrm{O}_{2}{ }^{2-}$ with $U \mathrm{UVC} / \mathrm{H}_{2} \mathrm{O}_{2}$ in terms of efficiency and cost for the removal of micropollutants from groundwater. Chernosphere, 119(Supplement), 81-88.

https://doi.org/10.1016/j.chemosphere.2014.03.029

\section{General rights}

Copyright and moral rights for the publications made accessible in the public portal are retained by the authors and/or other copyright owners and it is a condition of accessing publications that users recognise and abide by the legal requirements associated with these rights.

- Users may download and print one copy of any publication from the public portal for the purpose of private study or research.

- You may not further distribute the material or use it for any profit-making activity or commercial gain

- You may freely distribute the URL identifying the publication in the public portal 
This is a Post Print of the article published online $16^{\text {th }}$ April 2014 and printed January 2015 in Chemosphere, 119 , S81-S88. The publishers' version is available at the permanent link: dx.doi.org/10.1016/j.chemosphere.2014.03.029

\section{Comparison of $\mathrm{UVC} / \mathrm{S}_{2} \mathrm{O}_{8}{ }^{2-}$ with $\mathrm{UVC} / \mathrm{H}_{2} \mathrm{O}_{2}$ in terms of efficiency and cost for the removal of micropollutants from groundwater}

Maria G. Antoniou ${ }^{1,2 *}$ and Henrik R. Andersen ${ }^{1}$

${ }^{1}$ Technical University of Denmark (DTU), Department of Environmental Engineering, Miljøvej, Building 113, 2800 Kgs. Lyngby

${ }^{2}$ Cyprus University of Technology Department of Environmental Science and Technology, Corner of Athinon and Anexartisias 57, PO Box: 50329, 3603 Lemesos, Cyprus. "Corresponding authors e-mail: maria.antoniou@cut.ac.cy

\section{Highlights}

- Cost comparison of UVC/HP and UVC/PS for groundwater treatment.

- UVC/PS performed better for atrazine removal in Milli-Q water.

- UVC/HP had a better overall performance for the removal of the mixture of contaminants.

- Results from the collimated beam apparatus were comparable to the flow-through system.

- UVC/PS is economically feasible for special matrices where selective oxidation is required.

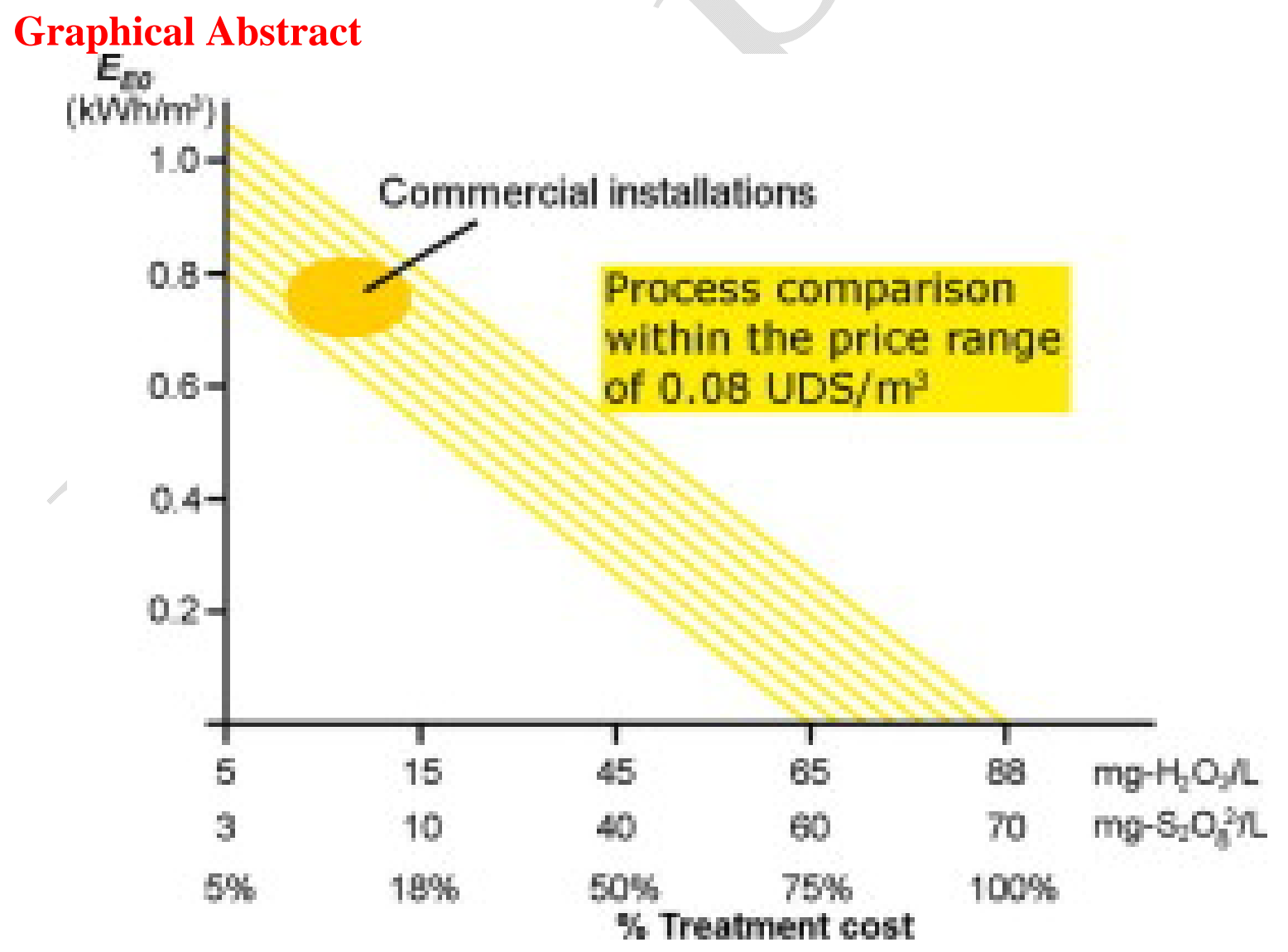




\begin{abstract}
This study compared the $\mathrm{UVC} / \mathrm{S}_{2} \mathrm{O}_{8}{ }^{2-}$ system with the more commonly used AOP in water industry, $\mathrm{UVC} / \mathrm{H}_{2} \mathrm{O}_{2}$, and examined whether the first one can be an economically feasible alternative technology. Atrazine and 4 volatile compounds (methyl tert-butyl ether, cisdichlorethen, 1,4-dioxane and 1,1,1-trichloroethane) were chosen as model contaminants because they exhibit different susceptibility to UVC photolysis and AOPs. A collimated beam apparatus was utilized for the majority of the experiments (controlled environment, without mass transfer phenomena), while selected experiments were performed in a flow-through reactor to simulate industrial applications. Initial experiments on the activation of oxidants with a LP lamp indicated that $\mathrm{S}_{2} \mathrm{O}_{8}{ }^{2-}$ is photolysed about 2.3 times faster than $\mathrm{H}_{2} \mathrm{O}_{2}$ and that the applied treatment times were not sufficient to utilize the majority of the oxidant. The effect of oxidants' concentrations were tested with atrazine alone and in the micropollutants' mixture and it was decided to use $11.8 \mathrm{mg} / \mathrm{L} \mathrm{S}_{2} \mathrm{O}_{8}{ }^{2-}$ and $14.9 \mathrm{mg} / \mathrm{L} \mathrm{H}_{2} \mathrm{O}_{2}$ for further testing since is closer to industrial applications and to minimize the residual oxidant concentration. Changes of the matrix composition of the treated water were investigated with the addition of chloride, bicarbonate and humic acids at concentrations relevant to a well-water-sample, the results showed that the system least affected was $\mathrm{UVC} / \mathrm{H}_{2} \mathrm{O}_{2}$. Only when bicarbonate was used, $\mathrm{UVC} / \mathrm{S}_{2} \mathrm{O}_{8}{ }^{2-}$ performed better. Overall, testing these systems with the mixture of micropollutants gave better insights to their efficiency than atrazine alone and $\mathrm{UVC} / \mathrm{S}_{2} \mathrm{O}_{8}{ }^{2-}$ is recommended for selective oxidation of challenging matrices.
\end{abstract}

\title{
1. Introduction
}

Modern living requires the usage of myriads of xenobiotics including pesticides, pharmaceuticals, personal care products, and solvents that find their way into the natural environment (Antoniou et al., 2013; de la Cruz et al., 2011; Esperanza et al., 2007; Hansen et al., 2010; Hansen et al., 2012; Marfil-Vega et al., 2011). Though found at small concentrations (thus are commonly known as micropollutants) they can still have adverse effects in the ecosystem. Advances in analytical instrumentation allowed the detection of these micropollutants even at the ppt level. Water resources are particularly susceptible to micropollutant contamination, especially surface and ground water. To address this issue, Environmental Agencies worldwide have frequently updated lists of potent contaminants and their maximum allowable concentrations. Based on the potency of a compound its complete elimination from the environment may be required (Li et al., 2013; USEPA CCL3, WFD 2000).

Ground water is a significant source of potable water. Since natural filtration of ground water is not sufficient to remove these recalcitrant contaminants, further treatment is required. The characteristics of ground water include low TOC values (few $\mathrm{mg} / \mathrm{L}$ ) with high alkalinity, making its treatment quite challenging (Antoniou and Andersen, 2012). With conventional treatment processes having limited ability in removing these compounds, chemical oxidation technologies and specifically advanced oxidation processes (AOPs) are currently been tested. AOPs are utilizing radiation, oxidants and/or catalysts for the generation of highly oxidizing species, known as free radicals. Free radicals are atoms or molecules that have unpaired valance electrons (odd number of electrons), which makes them particularly reactive. They can be stabilized by taking electrons from nearby compounds through $\mathrm{e}^{-}$abstraction, and reactions of addition, substitution, oxidation, and bond cleavage (Antoniou et al., 2008; Antoniou et al., 2010b; Li et al., 2013; Stefan and Bolton, 1998). Hydroxyl radicals (HO') are the most commonly used radicals in drinking water treatment because of their low selectivity and high reactivity with 
organic compounds (Buxton et al., 1988). Many processes can lead to the formation of $\mathrm{HO}^{\bullet}$ as the primary or secondary oxidizing specie including light and heat activation of hydrogen peroxide $\left(\mathrm{H}_{2} \mathrm{O}_{2}\right), \mathrm{TiO}_{2}$ photocatalysis, sonication, and ozonolysis (Antoniou et al., 2008; Buxton et al., 1988). Commercial applications of the $\mathrm{UV} / \mathrm{H}_{2} \mathrm{O}_{2}$ system such as the ones found at $\mathrm{PWN}$, Netherlands and the Aurora Reservoir of the Orange Country, CA, USA, ran at 5-6 mg/ $\mathrm{L} \mathrm{H}_{2} \mathrm{O}_{2}$ and around 0.7 to $0.8 \mathrm{kWh} / \mathrm{m}^{3}$-water-treated used for UV light (Kruithof et al., 2007; Linden and Rosenfeldt, 2011).

The low selectivity of $\mathrm{HO}^{\bullet}$ results in the oxidation of any component of the treated water matrix. Since these micropollutants are found in two to three orders of magnitude lower concentrations that the remaining matrix components, a lot of the active species (and therefore the added oxidant) are consumed by the matrix (Antoniou et al., 2013). To resolve this, alternative types of radicals and specifically sulfate radicals $\left(\mathrm{SO}_{4}{ }^{\circ}\right)$ are currently being investigated because they have higher selectivity for oxidation and higher standard redox potentials than $\mathrm{HO}^{\bullet}$ for the abstraction of electrons (Anipsitakis and Dionysiou, 2004; Antoniou et al., 2010a; Antoniou et al., 2010b).

Based on the above, this study aimed to explore the potential applications of sulfate radicalbased AOPs for ground water treatment. Specifically, the UVC/persulfate $\left(\mathrm{S}_{2} \mathrm{O}_{8}{ }^{2-}\right)$ system was compared to the most commonly industrially used UV-based AOP, $\mathrm{UVC} / \mathrm{H}_{2} \mathrm{O}_{2}$, to evaluate whether the first one can be applied as a resource and financially competitive treatment. Initially, the focus was on the comparison between the efficiencies of the treatments for micropollutant removal at equal oxidant cost concentrations rather than molarities. The pricing of commercial applications to achieve $90 \%$ of atrazine removal from an initial concentration of $1 \mu \mathrm{g} / \mathrm{L}$ is estimated to be $0.08 \mathrm{USD} / \mathrm{m}^{3}$ treated water (Rosenfeldt et al., 2006). Since this value is used as a design point for commercial applications, the oxidant concentrations were chosen to remain within the targeted pricing point of $0.08 \mathrm{USD} / \mathrm{m}^{3}$ (Scheme A1, Table A4, Appendix A). Atrazine, methyl tert-butyl ether (MTBE), 1,4-dioxane, cis-dichlorethene (DCE) and 1,1,1trichlorethane) (Table A1) were chosen as model compounds because they exhibit different susceptibilities to photolysis and AOPs. Atrazine and cis-DCE can both be photolysed and they are targets for selective oxidation by sulfate radicals, due to their $\pi$-electrons in their double bonds (Antoniou et al., 2008; Antoniou et al., 2010b; Waldemer et al., 2007). MTBE and 1,4 dioxane are typically difficult treatment targets for most conventional water treatment methods and therefore are typically mentioned as target chemicals for $\mathrm{UVC} / \mathrm{H}_{2} \mathrm{O}_{2}$ (Burbano et al., 2002; Stefan and Bolton, 1998), while 1,1,1-trichlorethane is known to be resilient to chemical oxidation (Li et al., 2013; Nelson et al., 1990).

The experiments were initially performed in batch reactor vessels in a collimated beam (CB) apparatus with a low pressure (LP) UVC lamp. CB was preferred for initial testing since is a controlled environment without mass transfer limitations for reactions and even distribution of radiation from the source. After that, the focus was laid on the economy of the UV treatment by utilizing a flow through reactor equipped with LP lamp, closer to industrial applications, and performing experiments at different treatment levels $\left(\right.$ as $\left.\mathrm{kWh} / \mathrm{m}^{3}\right)$.

The experiments performed in the $\mathrm{CB}$ aimed to identify the photolysis kinetics that the two oxidants $\left(\mathrm{H}_{2} \mathrm{O}_{2}\right.$ and $\left.\mathrm{S}_{2} \mathrm{O}_{8}{ }^{2-}\right)$ follow. The competitive degradation kinetics of the five model compounds were determined for various oxidant concentrations and compared to atrazine alone. Based on the obtained data, the required UV dose causing $90 \%$ removal of each compound was determined. Finally, for the optimum oxidant concentrations, the matrix effects of the treated 
solution for UVC/PS and UVC/HP were assessed with a groundwater sample and three selected main matrix constituents (chloride, bicarbonate and humic acids) individually. To the best of our knowledge, this is the first study that evaluated the efficiency of these systems based on oxidant cost

\section{Materials and Methods}

\subsection{Experimental Set-up}

2.1.1 Collimated Beam (CB). Initially, the experiments were performed in a quasi-collimated beam apparatus to determine which oxidant concentrations are relevant and should be used further (flow through and matrix effects in CB) (Bolton and Linden, 2003). A low pressure lamp ( $\mathrm{P}=35 / 40 \mathrm{~W}$, UV Technik Gmbh, Wümbach) was used for illumination. For the experiments with atrazine alone, petri-dishes $(\mathrm{d}=7 \mathrm{~cm}$ and $\mathrm{h}=2 \mathrm{~cm})$ were used and the treated volume was 20 $\mathrm{mL}$. For the experiments with the mixture of all five compounds, petri-dishes of $\mathrm{d}=9 \mathrm{~cm}$ and $\mathrm{h}=$ $5 \mathrm{~cm}$ (treated volume $70 \mathrm{~mL}$ ) were utilized instead to avoid volatilisation. Samples were taken at predetermined time intervals for the quantification of atrazine in an HPLC (100 $\mu \mathrm{L}$ sample quenched with $100 \mu \mathrm{L}$ of $0.1 \mathrm{~g} / \mathrm{L} \mathrm{N} \mathrm{Na}_{2} \mathrm{~S}_{2} \mathrm{O}_{3}$ ) and for the quantification of the remaining compounds in the GC/MS (40 mL sample quenched with $2 \mathrm{~mL}$ of $1 \mathrm{~g} / \mathrm{L} \mathrm{Na}_{2} \mathrm{~S}_{2} \mathrm{O}_{3}$ ). The UV light was measured in radiation exposure minutes which can be converted to the fluency dose, $\mathrm{mJ} / \mathrm{cm}^{2}$ $\left(=\mathrm{mW} / \mathrm{sec} \cdot \mathrm{cm}^{2}\right)$ (Bolton, 2010).

2.1.2 Flow through reactor. Following the determination of the optimum oxidant concentration, selective experiments were repeated in the flow-through reactor, constructed specifically for the project (Scheme A2, Appendix A). Table A2 summarizes the dimensions of the reactor vessel (see Appendix A).

\subsection{Actinometry}

The UV irradiance of the CB apparatus was measured with the Protocol of Chemical Actinometry with Potassium Iodide established by Bolton and Stefan (Margolin et al., 2004). The experiments were conducted in petri dishes $(\mathrm{d}=9 \mathrm{~cm})$ and volume of actinometry solution was equal to $70 \mathrm{~mL}$. The irradiation occurred at a distance of $53.5 \mathrm{~cm}$ from the LP lamp and after $30 \mathrm{~s}$ of exposure to the lamp, the irradiance was estimated to be $7.27 \pm 0.19 \mathrm{~mW} /\left(\mathrm{cm}^{2} \cdot \mathrm{min}\right)$.

\subsection{Materials}

Model chemicals comprised of atrazine, MTBE, 1,4-dioxane, cis-dichlorethene (DCE) and 1,1,1trichlorethane were purchased from Sigma-Aldrich and used as received. A standard solution of atrazine was prepared with initial concentration $1 \mathrm{mg} / \mathrm{L}$. Aliquots were taken to prepare the treated solution for the $\mathrm{CB}$ experiments at $\mathrm{C}_{0}=200 \mu \mathrm{g} / \mathrm{L}$. For the experiments in the mixture, the concentration of atrazine was $\sim 100 \mu \mathrm{g} / \mathrm{L}$, while for the other compounds was $\sim 200 \mu \mathrm{g} / \mathrm{L}$. Dilute solutions of persulfate ( $\mathrm{PS}, \mathrm{Na}_{2} \mathrm{~S}_{2} \mathrm{O}_{8}$, Sigma) and hydrogen peroxide $\left(\mathrm{H}_{2} \mathrm{O}_{2}, 50 \%\right.$ solution, Sigma) used in the experiments were freshly prepared each time.

\subsection{HPLC}

Atrazine $(\mathrm{FW}=215.69)$ was quantified with an Agilent 1100 Series HPLC equipped with a variable wavelength detector (VWD). A $\mathrm{C}_{18}$ column $(46 \mathrm{~mm}$ x $15 \mathrm{~cm}, 5 \mu \mathrm{m}$ particle size) from 
Supelco Discovery was utilized. The eluent phase was 50:50 ACN: $\mathrm{H}_{2} \mathrm{O}$, with a flow rate of 0.5 $\mathrm{mL} / \mathrm{min}, \mathrm{T}_{\text {column }}=25.5^{\circ} \mathrm{C}$ and the detector set at $\lambda=220 \mathrm{~nm}$. Based on these conditions atrazine elutes at RT=8.2 min. A calibration curve with standard solution with concentrations $10-200$ $\mu \mathrm{g} / \mathrm{L}$ was conducted $\left(\mathrm{R}^{2}=0.999\right)$ and the method quantification limit was set at $5 \mu \mathrm{g} / \mathrm{L}$.

\subsection{Purge \& Trap-GC/MS}

The four semi-volatile model pollutants (cis-DCE, 1,4-Dioxan, MTBE, 1,1,1-trichlorethan) were analysed by placing samples in headspace free vials and analysing them by Purge \& TrapGC/MS. See appendix A for method details. See appendix A for method details.

\subsection{TOC}

A Shimadzu ASI-V UVC/Persulphate total organic carbon (TOC) analyzer was utilized for the quantification of the remaining carbon in the samples with the humic acid matrix. The sample injection volume was $3000 \mu \mathrm{L}$ and a calibration curve with standards from 50-2000 $\mu \mathrm{g} / \mathrm{L}$ was performed $\left(\mathrm{R}^{2}=0.9994\right)$. The method quantification limit is $50 \mu \mathrm{g} / \mathrm{L}$.

\subsection{Quantification of Residual Oxidant Concentration}

For the quantification of $\mathrm{H}_{2} \mathrm{O}_{2}$, the colorimetric method of TiO-oxalate was utilized (Mühlebach et al., 1970). For the quantification of persulfate, volumetric determination (titration) based on the method of Kolthoff and Carr (1953) was used (Kolthoff and Carr, 1953). More info is provided in Appendix A.

\subsection{Data Processing}

The obtained degradation data were normalized with their initial concentration and fitted using the GraphPad Prism 5 Software in order to calculate the $E_{E O}$ values of each compound at different oxidants concentrations according to the relation based on first order kinetic: $C / C_{0}=10^{-}$ $\mathrm{x} / \mathrm{EEO}$, where $\mathrm{C}$ is the concentration of the compound measured after delivering the UV dose, $\mathrm{x}$, $\left(\mathrm{mJ} / \mathrm{cm}^{2}\right.$ or $\mathrm{kWh} / \mathrm{m}^{3}$ for collimated beam reactor or flow through reactor, respectively) and $\mathrm{C}_{\mathrm{o}}$ is the concentration measured before any UV is delivered to the solution (Bolton, 2010). The fitting was based on optimizing relative distances squared.

\subsection{Experimental Design}

$\mathrm{UVC} / \mathrm{H}_{2} \mathrm{O}_{2}$ is considered to be state-of-the art technology for the treatment of municipal water, groundwater remediation, or water reuse. Treatment facilities that have currently incorporated this treatment process including the PWN in the Netherlands and the Aurora Reservoir or Orange Country, CA, USA are using $5-6 \mathrm{mg} / \mathrm{L} \mathrm{H}_{2} \mathrm{O}_{2}$ and around 0.7 to $0.8 \mathrm{kWh} / \mathrm{m}^{3}$ water treated (Kruithof et al., 2007; Linden and Rosenfeldt, 2011). The overall process cost can be therefore calculated by using the following pricing information: Energy $0.085 € / \mathrm{kWh} ; \mathrm{H}_{2} \mathrm{O}_{2} 1 € / \mathrm{kg}$; (Rosenfeldt et al., 2006) and the price of $\mathrm{Na}_{2} \mathrm{~S}_{2} \mathrm{O}_{8}$ is $130 \%$ more of $\mathrm{H}_{2} \mathrm{O}_{2}$ on a weight basis (based on EU and USA prices). This gives an approximate value of $0.08 \mathrm{USD} / \mathrm{m}^{3}$ for $90 \%$ atrazine removal (Kruithof et al., 2007).

In order for $\mathrm{UVC} / \mathrm{S}_{2} \mathrm{O}_{8}{ }^{2-}$ to be able to outperform the conventional $\mathrm{UVC} / \mathrm{H}_{2} \mathrm{O}_{2}$, the consumed energy and chemical costs for the tested $\mathrm{S}_{2} \mathrm{O}_{8}{ }^{2-}$ treatments must be lower than that of $\mathrm{H}_{2} \mathrm{O}_{2}$ in the same water matrixes since the other operational costs remain the same for both AOPs. 
In order to compare the two methods over a range of oxidant concentrations and still make the results comparable for the treatment cost we made an experimental design based on the known treatment cost of $0.08 \$ / \mathrm{m}^{3}$. We assumed that from 5 to $100 \%$ of cost this could be spend on any of the two oxidants and the remaining cost would thus cover the UV light. Based on this we defined 6 levels of oxidants in this range $(5.0,17.5,30.0,50.0,75.0100 .0 \%)$ for testing at which we determined the UV dose required to degrade the model chemicals. As the cost of the two oxidants are different, the oxidant doses would be different at the different levels but as the cost is the same it can be seen which treatment is optimal from the one requiring the lowest UV dose.

Based on $0.08 \mathrm{USD} / \mathrm{m}^{3}, \mathrm{H}_{2} \mathrm{O}_{2}$ concentrations start at $4.5 \mathrm{mg} / \mathrm{L}$, which is lower than the industrially used $6.0 \mathrm{mg} / \mathrm{L}$ (Kruithof et al., 2007) and reach 15 times higher values $(88 \mathrm{mg} / \mathrm{L}$ ). The respective $\mathrm{S}_{2} \mathrm{O}_{8}{ }^{2-}$ concentrations are also shown in Table A4 (see Appendix A), reaching from 3.5 to $70 \mathrm{mg} / \mathrm{L}$ of $\mathrm{Na}_{2} \mathrm{~S}_{2} \mathrm{O}_{8}$ (Table A4, Appendix A).

\section{Results and Discussion}

\subsection{Activation of Oxidants}

The percentage of oxidant activation following irradiation at different time intervals was first measured by analyzing the residual oxidant concentration (Fig. A3, Appendix A). The photolysis kinetics and estimated rates of decomposition of the oxidants HP and PS was thus determined at $0.30 \mathrm{mM}$ and $0.15 \mathrm{mM}$, respectively. Anipsitakis and Dionysiou (2004) reported that the molar extinction coefficient $(\varepsilon)$ of PS at $\lambda=254 \mathrm{~nm}$ is double than the corresponding coefficient of $\mathrm{HP}$ (Anipsitakis and Dionysiou, 2004). Based on this, it was decided to use the double molar concentration of HP compared PS in experiments, in order to have the same oxidants absorbance at $\lambda=254 \mathrm{~nm}$. PS is photolyzed $\sim 2.3$ times faster than HP, suggesting a higher quantum yield of PS photolysis compared to HP at $\lambda=254 \mathrm{~nm}$. When compared at the same molar concentration, PS appears to 'utilize' photons at $\lambda=254 \mathrm{~nm}$ approximately 5 times better than HP (Fig. A3, Appendix A). The reported quantum yields of PS $(\Phi=1,4$ (Mark et al., 1990)) and $\Phi=2,0$ (Yu et al., 2004) for deoxygenated and oxygenated solutions, respectively) are higher than the one of HP $(\Phi=1,0$ (Linden and Rosenfeldt, 2011)) confirming our results.

A lot of time (and therefore energy) is required to achieve complete oxidant decomposition. Many studies report increasing rate of degradation of target pollutants with increasing oxidant concentration (Antoniou et al., 2010a) but it is also necessary to know how much oxidant is utilized. Due to this, it is common practice in actual water treatment facilities to add a quenching agent or use a carbon filter to remove excess oxidant after the treatment (Linden and Rosenfeldt, 2011).

\subsection{Degradation of atrazine alone in pure water}

Experiments were conducted for the degradation of atrazine in Milli-Q water at different oxidant concentrations to investigate the irradiation time and thus irradiation dose needed to achieve one decade of atrazine removal. Since atrazine can be photolyzed with UVC radiation $\left(\lambda_{\max }=220 \mathrm{~nm}\right.$, $\Phi=0.05$ at $\lambda=254 \mathrm{~nm}$ ), in the absence of oxidants around $35 \%$ of atrazine was removed at the highest irradiance of $290 \mathrm{~mJ} / \mathrm{cm}^{2}$ (Linden and Rosenfeldt, 2011). The UVC/PS system significantly stimulates the degradation of atrazine compared to UVC/HP for all the oxidant concentrations tested except the lowest one (Fig. A4, Appendix A). Given that the added 
oxidants are compared based on cost and not molarity (HP's concentration is 9 times of PS's, Table A4, Appendix A) it's derived that the significantly lower PS concentration could not be counteracted by its higher quantum yield. In addition, it is understood that the irradiation time required to achieve $90 \%$ atrazine removal is quite short (Fig. A4, Appendix A) compared to the irradiation time required for maximum oxidant decomposition (Fig. A3, Appendix A). This may have also contributed to the low reactivity exhibited by PS at $5.0 \%$.

\subsection{Degradation of model chemicals in pure water}

Experiments with all the model chemicals were conducted by varying the oxidant concentration and irradiation time (noted on the graphs as UV-doses $\mathrm{mJ} / \mathrm{cm}^{2}$ ). The actual results on the remaining contaminant concentration are shown in Fig. 1. The same data where fitted to the first order kinetic model (Bolton, 2010) which determined the predicted radiation dose for $90 \%$ removal of the model contaminant $\left(E_{E O}\right)$ for each oxidants concentrations as shown in Fig. 2. 1,1,1-Trichlorethane proved to be extremely recalcitrant towards oxidation, the kinetic model could not be properly fitted and therefore, the corresponding $E_{E O}$ is not displayed in Fig. 2.

Overall, atrazine was the only compound that was photolysed in the absence of oxidants, cisDCE had the highest degradation rates for both oxidants, and 1,1,1-trichlorethane was the most resilient to oxidation at all tested conditions. Based on Fig. 1 and 2, the order of increased degradation efficiency for $\mathrm{UVC} / \mathrm{HP}$ is $1,1,1$-trichlorethane $<\mathrm{MTBE}<$ atrazine $=1,4$ dioxane $<$ $\mathrm{DCE}$ and for UVC/PS is 1,1,1-trichlorethane $<\mathrm{MTBE}<1,4$ dioxane $<$ atrazine $<$ DCE. The obtained orders can also be explained in terms of the contaminants' structures. The double carbon bonds of DCE can undergo attack by both sulfate and hydroxyl radicals through mechanisms of hydroxyl addition or substitution (Antoniou et al., 2010b; Waldemer et al., 2007). 

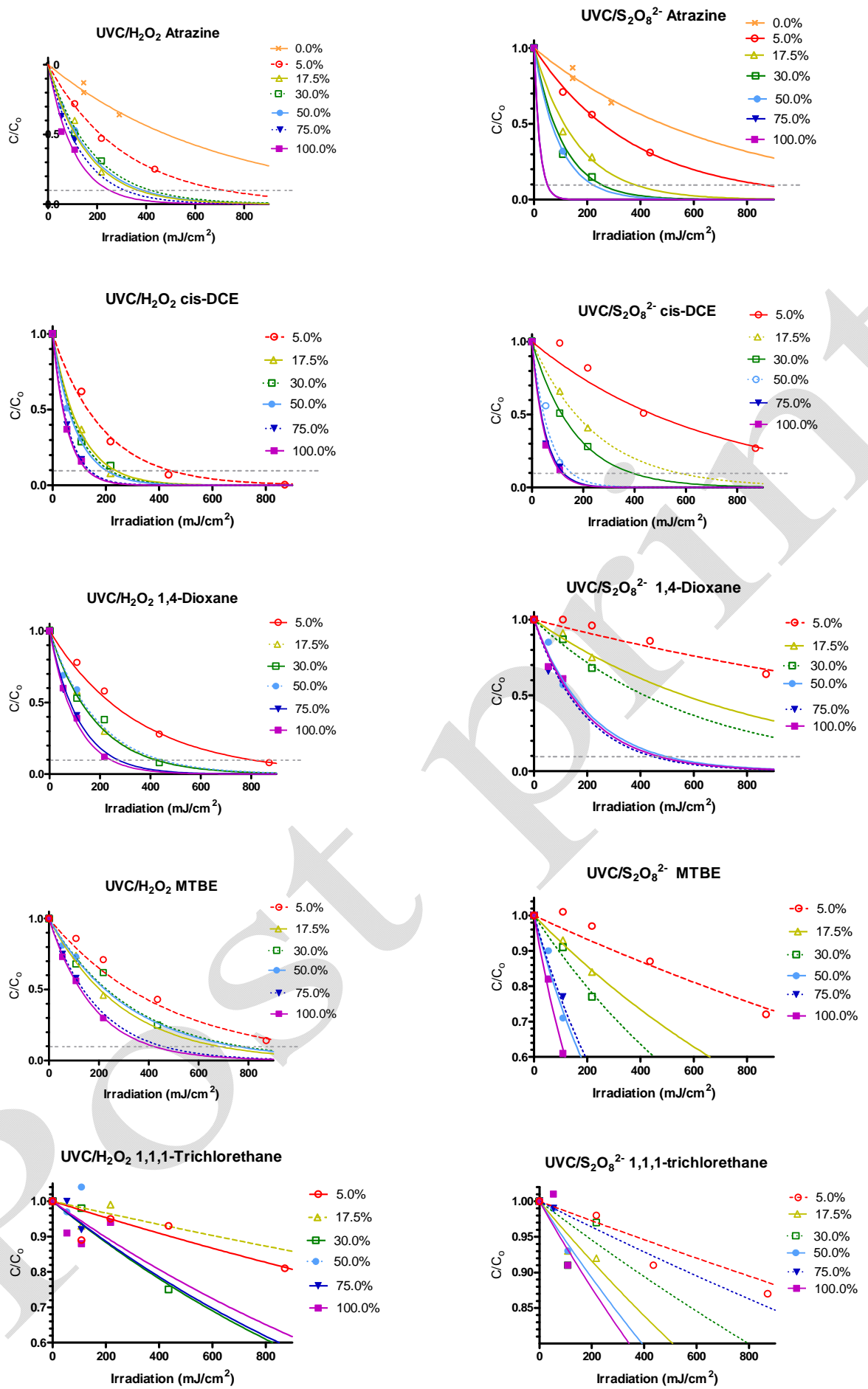

Figure 1: Degradation of the model chemicals with UVC radiation for different concentrations of the two oxidants. 

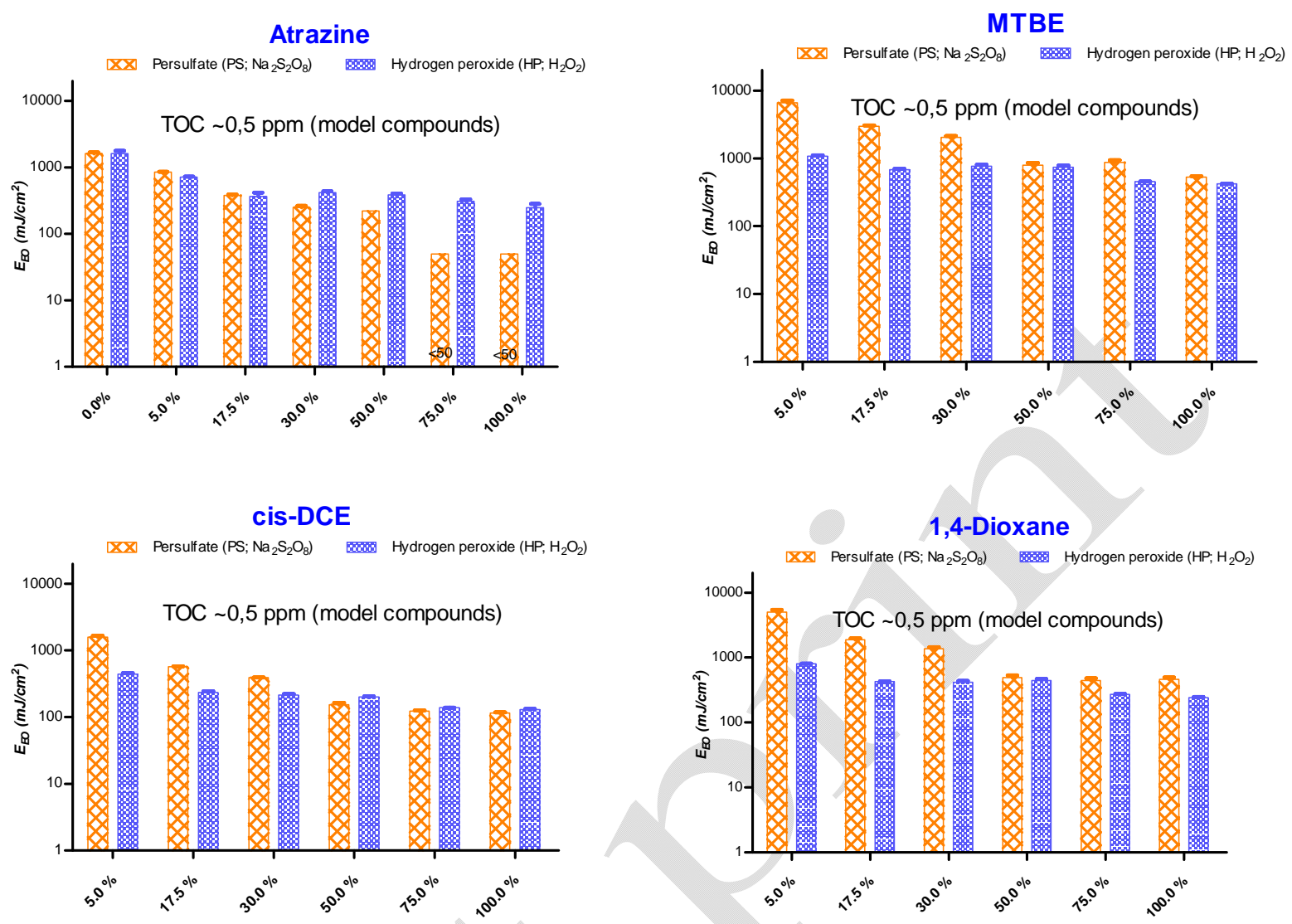

Figure 2: Required irradiation time for reaching $90 \%$ removal of the model chemicals $\left(E_{E O}\right)$ in pure water as a function of the initial oxidant concentration expressed as percentage of overall cost. The values are found by fitting the kinetics of degradation to the data shown in Fig. 1.

Atrazine is susceptible to hydroxyl substitution and bond cleavage (Balci et al., 2009; Bandala et al., 2007) but heteroatoms in the aromatic ring reduce the second order rate constants for reaction with the radicals (Antoniou et al., 2009). 1,4 dioxane, MTBE, and 1,1,1-trichlorethane undergo $\mathrm{e}^{-}$ abstraction with both radicals but at different rates because of the presence of heteroatoms in their structures and shielding.

In terms of the effect of oxidant concentration, atrazine appears to be removed with equal effectiveness for the two lowest oxidant cost values, but as the concentration increases, PS becomes increasing more efficient. The same effect is seen for cis-DCE but at lesser extent. The remaining two compounds, 1,4-dioxane and MTBE appear to exhibit similar behaviour: for the low oxidant concentrations, UVC/HP degrades these model chemicals considerably more effectively, but once half of the treatment cost or more is spend on the oxidants, UVC/HP and $\mathrm{UVC} / \mathrm{PS}$ perform similarly. This means that in order for the UVC/PS to be a cost competitive treatment of UVC/HP for all the micropollutants in Milli-Q water, more than half the treatment cost needs to be spend on the oxidant ( $>0.04$ USD). Even then, UVC/PS became competitive at higher oxidant concentrations but it still remained below or just reached the degradation yields of UVC/HP. Based on the efficiencies of the different oxidant concentrations with the mixture (Fig. 2) and the fact that only a small portion of the oxidant is activated during the tested treatment 
times (Fig. A3, Appendix A), only one oxidant concentration was tested at $17.5 \%$ of overall cost (corresponding to $11.8 \mathrm{mg} / \mathrm{L}$ and $14.9 \mathrm{mg} / \mathrm{L}$ for PS and HP, respectively). It is important to note that the results of Fig. 2 also emphasize the significance of testing emerging treatment technologies with mixtures of competitive contaminants, to get a better overview of their performance and optimum operational conditions.

\subsection{Degradation of model contaminants in different water matrices}

Traditional matrix components which are known to interfere considerably with the efficiency of AOPs are chloride, bicarbonate and humic acids (Antoniou and Andersen, 2012; Linden and Rosenfeldt, 2011; Pelaez et al., 2011). These compounds are usually found in excess in the treated water compared to the target compounds and can quench the in situ generated radical species, prohibiting reaction with target contaminants. In this study, the effect of each component was tested individually along with a groundwater sample taken from the DTU tap water. It was decided to use tap water from the DTU-Campus which is based on well water, because it has high alkalinity $\left(\mathrm{HCO}_{3}{ }^{-}=332 \mathrm{mg} / \mathrm{L}\right)$ and a considerable concentration of "aged" NOM (DOC $2.5 \mathrm{mg} / \mathrm{L}$ ) from a deep-well source water and therefore, comprises a challenge for AOP treatment (Antoniou and Andersen, 2012). As previously mentioned, only one oxidant concentration was tested at $17.5 \%$ of overall cost (corresponding to $11.8 \mathrm{mg} / \mathrm{L}$ and $14.9 \mathrm{mg} / \mathrm{L}$ for PS and HP, respectively) and the results are summarized in Fig. 3.

The conclusion of the competitive experiments shown in Fig. 3 is that at the tested oxidant concentration, contaminant degradation is only favourable if the target chemical shows some selectivity towards sulfate radical oxidation, while the water matrix does not contain easily degradable components such as aromatic rings. Advantageous matrix component for the UVC/PS system appears to be bicarbonate (Fig. 3) especially for atrazine. Humic acids, on the other hand, which are known to have many easily degradable functional groups, including aromatic rings, are targeted for oxidation by the both hydroxyl and sulfate radicals (Buxton et al., 1988; Neta et al., 1988). As before, 1,1,1-trichlorethane did not properly fit the kinetic model and therefore the corresponding graph is not displayed. 

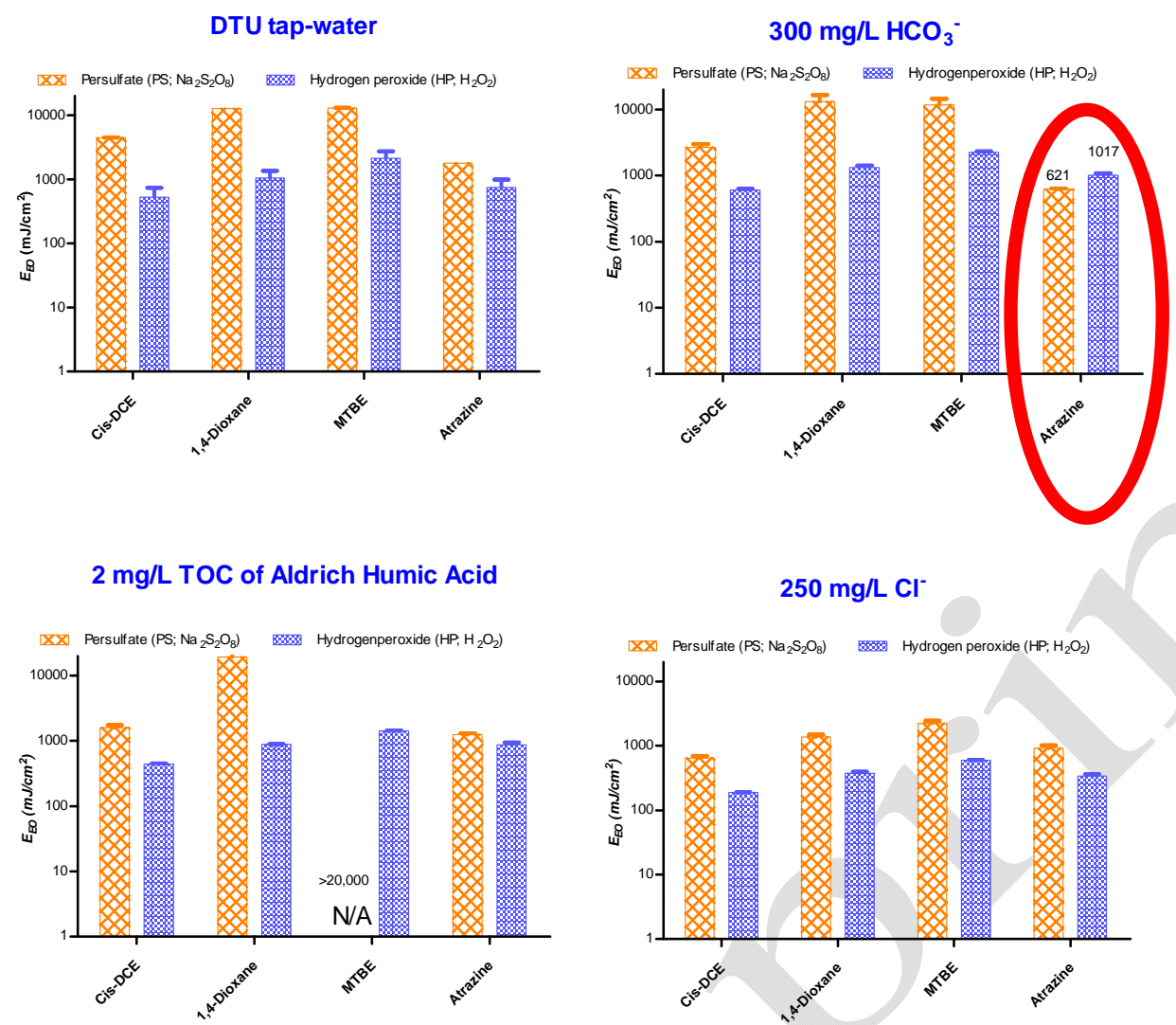

Figure 3: Effect of matrix interference on required UVC-dose for degradation of the model compounds at a single oxidant dose at $17.5 \%$ of cost (PS $11.8 \mathrm{mg} / \mathrm{L}$ and HP $14.9 \mathrm{mg} / \mathrm{L}$ ). The matrices are DTU tap water and each of the main matrix components bicarbonate, chloride and humic acid separately (used at a realistic but on the higher-end concentrations).

\subsection{Flow through experiments}

For the degradation of the mixture in the flow through experiments demineralized (DI) water and DTU-Tap water were utilized (Fig. 4). The oxidants concentrations tested were at $17.5 \%$ of oxidant cost. The flow rates tested were 40,80 and $133 \mathrm{~L} / \mathrm{h}$ which correspond to $1.0,0.5$ and 0.3 $\mathrm{kWh} / \mathrm{m}^{3}\left(\mathrm{P}_{\mathrm{LP}}=40 \mathrm{~W}\right)$. 
HP DI

HP TAP
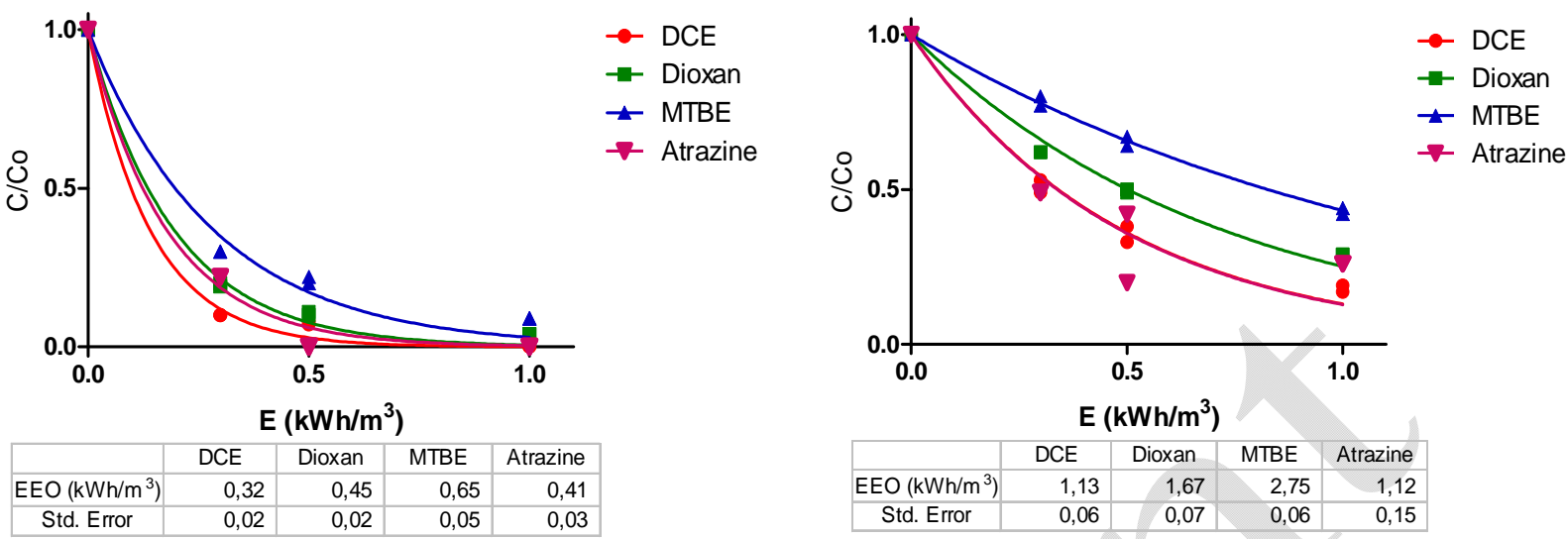

PS DI

PS TAP
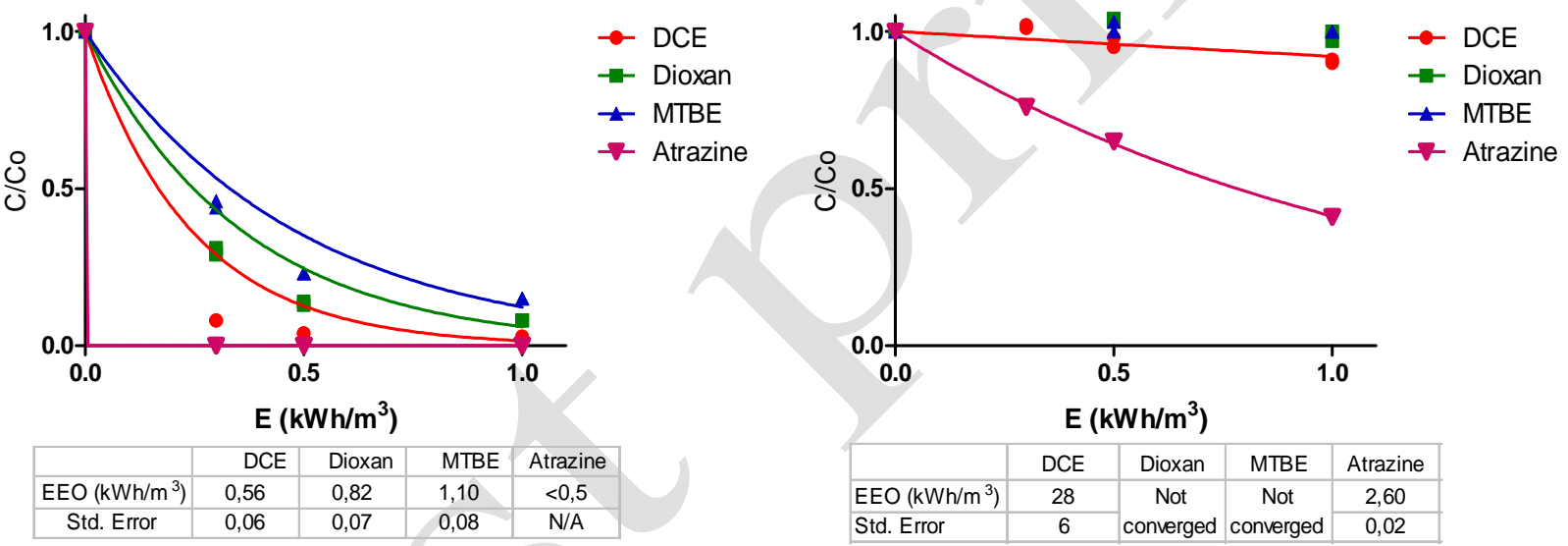

Figure 4: Comparison of UVC/HP and UVC/PS in demineralised water (DI) and DTU-Tap water in the flow through reactor with LP lamp.

Both oxidants were very efficient for the removal of the four compounds (atrazine, DCE, MTBE and dioxane) from DI water with PS requiring approximately double the EEOs for all of them. The difference between the efficiencies of the oxidants became even more apparent once the ground water matrix (DTU-tap water) was used with the EEOs increasing by a factor of 2-4 for HP and $>50$ for PS between tap and DI water.

The reduction in the degradation efficiencies for all the compounds for both the oxidants in the tap-water is possibly due to the presence of radical scavengers $\left(332 \mathrm{mg} / \mathrm{L} \mathrm{HCO}_{3}{ }^{-}\right)$and organic impurities $(2.0 \mathrm{mg} / \mathrm{L}$ TOC). UVC/PS appears to be more affected by the DTU-tap water matrix since only DCE was significantly removed but at notably lower rates to UVC/HP. UVC/HP performed better for both water matrixes. 1,1,1-Trichlorethane, though present in the treated solution, did not degrade significantly and was therefore omitted from the graphs of Fig. 4. 


\section{Conclusions}

The feasibility of $\mathrm{UVC} / \mathrm{S}_{2} \mathrm{O}_{8}{ }^{2-}$ and $\mathrm{UVC} / \mathrm{H}_{2} \mathrm{O}_{2}$ for the removal of a mixture of micropollutants from groundwater was investigated. The initial experiments on the oxidants' activation in the $\mathrm{CB}$ showed that a small percentage of oxidant is activated therefore; it is economically more profitable to spend the majority of the cost on the UV lamps than the oxidants. When atrazine was treated alone, UVC/PS was more efficient than UVC/HP, however when the mixture of compounds was used, UVC/HP performed overall better. This means that if only atrazine was used as a model compound, misleading conclusions would have been made because of the lack of competition for radical degradation.

The ground water sample and the matrix components chloride, and humic acids had the least effect on the UVC/HP, with the exception of bicarbonate that performed better with UVC/PS. Finally, the flow through reactor showed the same efficiencies of the two systems as with the CB apparatus, validating our decision to use the $\mathrm{CB}$ as a design tool for the experimental conditions.

In conclusion, the UVC/PS system was found not to be an economically competitive against $\mathrm{UVC} / \mathrm{HP}$ in the tested water matrixes which are commonly found in water and ground water applications. UVC/PS, however, was found competitive for selective oxidation in special water (or wastewater) matrices with high organic content and alkalinity.

\section{Acknowledgments}

This research was funded by Siemens AG Water Technologies. Special thanks for the support go to the Head of Technology, Siemens Industry, Prof. Dr.-Ing. Dieter Wegener. The authors would like to thank the technicians Christina Maj Hagberg, and Jens Schaarup Sørensen of DTUEnvironment for their assistance.

\section{References}

Anipsitakis, G.P., Dionysiou, D.D., 2004. Transition metal/UV-based advanced oxidation technologies for water decontamination. Appl Catal B- Environ. 54, 155-163.

Antoniou, M.G., Andersen, H.R., 2012. Evaluation of pretreatments for inhibiting bromate formation during ozonation. Environ Technol (United Kingdom). 33, 1747-1753.

Antoniou, M.G.,Shoemaker, J.A., De La Cruz, A.A., Dionysiou, D.D., 2008. Unveiling New Degradation Intermediates/ Pathways from the Photocatalytic Degradation of Microcystin-LR, Environ Sci Technol. 42, 8877-8883.

Antoniou, M.G., de la Cruz, A.A., Dionysiou, D.D., 2010a. Degradation of microcystin-LR using sulfate radicals generated through photolysis, thermolysis and e- transfer mechanisms. Appl Catal B- Environ. 96, 290-298.

Antoniou, M.G., De La Cruz, A.A., Dionysiou, D.D., 2010b. Intermediates and reaction pathways from the degradation of microcystin-LR with sulfate radicals. Environ Sci Technol. 44, 7238-7244. 
Antoniou, M.G., Hey, G., Rodríguez Vega, S., Spiliotopoulou, A., Fick, J., Tysklind, M., la Cour Jansen, J., Andersen, H.R., 2013. Required ozone doses for removing pharmaceuticals from wastewater effluents. Sci. Total Environ. 456-457, 42-49.

Antoniou, M.G., Nambiar, U., Dionysiou, D.D., 2009. Investigation of the photocatalytic degradation pathway of the urine metabolite, creatinine: The effect of $\mathrm{pH}$. Water Res. 43, 39563963.

Balci, B., Oturan, N., Cherrier, R., Oturan, M.A., 2009. Degradation of atrazine in aqueous medium by electrocatalytically generated hydroxyl radicals. A kinetic and mechanistic study. Water Res. 43, 1924-1934.

Bandala, E.R., Domínguez, Z., Rivas, F., Gelover, S., 2007. Degradation of atrazine using solar driven fenton-like advanced oxidation processes. Journal of Environmental Science and Health Part B Pesticides, Food Contaminants, and Agricultural Wastes. 42, 21-26.

Bolton, J.R., 2010. Ultraviolet Applications Handbook, 3 ed. Bolton Photosciences Inc.

Bolton, J.R., Linden, K.G., 2003. Standardization of methods for fluence (UV Dose) determination in bench-scale UV experiments. J. Environ. Eng. 129, 209-215.

Burbano, A.A., Dionysiou, D.D., Richardson, T.L., Suidan, M.T., 2002. Degradation of MTBE intermediates using Fenton's reagent. J. Environ. Eng. 128, 799-805.

Buxton, G.V., Greenstock, C.L., Helman, W.P., Ross, A.B., 1988. Critical review of rate constants for reactions of hydrated electrons, hydrogen atoms and hydroxyl radicals in aqueous solution. J. Phys. Chem. Ref. Data. 17, 513-886.

de la Cruz, A.A., Antoniou, M.G., Hiskia, A., Pelaez, M., Song, W., O'Shea, K.E., He, X., Dionysiou, D.D., 2011. Can we effectively degrade microcystins? - Implications on human health. Anticancer Agents Med Chem. 11, 19-37.

Esperanza, M., Suidan, M.T., Marfil-Vega, R., Gonzalez, C., Sorial, G.A., McCauley, P., Brenner, R., 2007. Fate of sex hormones in two pilot-scale municipal wastewater treatment plants: Conventional treatment. Chemosphere. 66, 1535-1544.

Hansen, K.M.S., Andersen, H.R., Ledin, A., 2010. Ozonation of estrogenic chemicals in biologically treated sewage. Water Sci Technol. 62, 649-657.

Hansen, K.M.S., Willach, S., Mosbæk, H., Andersen, H.R., 2012. Particles in swimming pool filters - Does $\mathrm{pH}$ determine the DBP formation? Chemosphere. 87, 241-247.

Kolthoff, I.M., Carr, E.M., 1953. Volumetric determination of persulfate in the presence of organic substances. Anal. Chem. 25, 298-301.

Kruithof, J.C., Kamp, P.C., Martijn, B.J., 2007. UV/ $\mathrm{H}_{2} \mathrm{O}_{2}$ treatment: A practical solution for organic contaminant control and primary disinfection. Ozone Sci. Eng. 29, 273-280.

Li, B., Li, L., Lin, K., Zhang, W., Lu, S., Luo, Q., 2013. Removal of 1,1,1-trichloroethane from aqueous solution by a sono-activated persulfate process. Ultrason. Sonochem. 20, 855-863. 
Linden, K.G., Rosenfeldt, E.J., 2011. Chapter 18: Ultraviolet Light Processes. In: Edzwald, J.K. (Ed.). Water Quality \& Treatment. A Handbook on Drinking Water. American Water Works Association, pp. 18.1-18.45.

Marfil-Vega, R., Suidan, M.T., Mills, M.A., 2011. Assessment of the abiotic transformation of 17ß-estradiol in the presence of vegetable matter. Chemosphere. 82, 1468-1474.

Margolin, A., Malley, J.M., Linden, K.G., Ballester, N., Mofidi, A., 2004. Inactivation of Pathogens with Innovative UV Technologies. American Water Works Association.

Mark, G., Schuchmann, M.N., Schuchmann, H.-., von Sonntag, C., 1990. The photolysis of potassium peroxodisulphate in aqueous solution in the presence of tert-butanol: a simple actinometer for $254 \mathrm{~nm}$ radiation. J. Photochem. Photobiol., A: Chem. 55, 157-168.

Mühlebach, J., Müller, K., Schwarzenbach, G., 1970. The peroxo complexes of titanium. Inorg. Chem. 9, 2381-2390.

Nelson, L., Shanahan, I., Sidebottom, H.W., Treacy, J., Nielsen, O.J., 1990. Kinetics and mechanism for the oxidation of 1,1,1-trichloroethane. Int J Chem Kinet. 22, 577-590.

Neta, P., Huie, R.E., Ross, A.B., 1988. Rate constants for reactions of inorganic radicals in aqueous solution. J.Phys.Chem.Ref.Data. 17, 1027-1284.

Pelaez, M., de la Cruz, A.A., O'Shea, K., Falaras, P., Dionysiou, D.D., 2011. Effects of water parameters on the degradation of microcystin-LR under visible light-activated $\mathrm{TiO}_{2}$ photocatalyst. Water Res. 45, 3787-3796.

Rosenfeldt, E.J., Linden, K.G., Canonica, S., von Gunten, U., 2006. Comparison of the efficiency of $\mathrm{OH}$ radical formation during ozonation and the advanced oxidation processes $\mathrm{O}_{3} / \mathrm{H}_{2} \mathrm{O}_{2}$ and $\mathrm{UV} / \mathrm{H}_{2} \mathrm{O}_{2}$. Water Res. 40, 3695-3704.

Stefan, M.I., Bolton, J.R., 1998. Mechanism of the degradation of 1,4-dioxane in dilute aqueous solution using the UV/hydrogen peroxide process. Environmental Science and Technology. 32, 1588-1595.

USEPA CCL3, Contaminant Candidate List 3 - CCL

http://water.epa.gov/scitech/drinkingwater/dws/ccl/ccl3.cfm\#ccl3 (last access $31^{\text {st }}$ January,2014).

Waldemer, R.H., Tratnyek, P.G., Johnson, R.L., Nurmi, J.T., 2007. Oxidation of chlorinated ethenes by heat-activated persulfate: Kinetics and products. Environ Sci Technol. 41, 1010-1015.

WFD 2000, Directive 2000/60/EC of the European Parliament and of the Council of 23 October 2000 establishing a framework for Community action in the field of water policy http://eur-lex.europa.eu/LexUriServ/LexUriServ.do?uri=OJ:L:2000:327:0001:0072:EN:PDF.

(last access $31^{\text {st }}$ January, 2014).

Yu, X., Bao, Z., Barker, J.R., 2004. Free Radical Reactions Involving Cl, Cl2-, and SO4-in the $248 \mathrm{~nm}$ Photolysis of Aqueous Solutions Containing S2O82-and Cl. J. Phys. Chem. A. 108, 295308. 